\title{
Combined art and science as a communication pathway in a primary school setting: paper and ice
}

\section{Gabby O'Connor and Craig Stevens}

\begin{abstract}
A hybrid combination of art and science is used to communicate science in a primary school setting. The purpose of the work is to enhance student awareness of the science behind understanding the global climate system with a focus on the cryosphere. An experiment in communicating science is conducted by taking the collaborative experiences of a professional artist and scientist, which are then combined and projected onto an ostensibly everyday primary school classroom project. The tangible end result is a stand-alone contemporary art work that then is the focal point of community-based promotion of the science and creativity involved. A range of qualitative evaluation elements suggest that the approach does improve student engagement with the scientific approach and reduces the student's uncertainty about "what science is".
\end{abstract}

Keywords

Public engagement with science and technology; Science and technology, art and literature; Science education

The openness and adaptability of primary school age students to new ideas and concepts is in direct contrast to later stages of intellectual development [Nelson, 2000]. Nowhere is this more clear that the gulf between art and science, with separation generally evolving in early secondary school. Early primary school students instead have little or no agenda and few preconceptions, except perhaps that scientists "wear white laboratory coats" and artists "carry a messy paint palette". There is an element of plasticity in learning so that some behaviours evolve and in doing so set the scene for later development and are not easily reconfigured. [Nelson, 2000].

Art and play are seen as the earliest learning strategies [McArdle and Wright, 2014]. Furthermore, advanced creativity is multifaceted and something that is not simply inherent, but can be nurtured and developed with multiple benefits. Here we leverage off the continuum in creativity between art and science and that, especially at primary school levels, this tendency towards art and play can diffract and aid in engagement, with a wide range of outcomes in understanding. In the present work we use the term "engagement" in the sense of enhancing the audience's sense of level of involvement in the scientific process, albeit through the parallel creative pathway of art. Principally, this results in examination of the art-science nexus and its role in creativity - the creation of new 
understanding/knowledge/appreciation. To make major advances artists use and break rules, often in the same way that scientists do. They both can be defined and constrained by the technology they use. The best of both seek to take understanding and experience beyond where we are now. Insomuch as creativity can be quantified [Wolfradt and Pretz, 2001], connection between enhanced creativity and openness to ideas is apparent.

Here we describe an approach to enhancing science communication by connecting between art, science and understanding using the frozen (and melting) environment of Antarctica which implicitly appeals to, and fosters, openness of thought. This is because Antarctica is an environment that occupies a special place in the imagination of many peoples as being "the unknown". Not only that, the cryosphere is a central theme in earth system science especially around how it influences a range of processes from atmospheric and oceanic circulation through to high-latitude ecosystems (i.e. in the context of primary school students thinking this is largely polar bears, penguins, whales and seals).

The communication experiment described here supports a number of underpinning ideas about the development of science. Primary amongst these is that art and science access creative minds in much the same way [Andreasen and Ramchandran, 2012]. Furthermore, development in ideas extends from incremental gains through to paradigm shifts [Kuhn, 1962]. A consequence of this is, while the classroom environment would normally like to access monolithic results [Hadzigeorgiou, Fokialis and Kabouropoulou, 2012], on-going development of ideas must also be accommodated. In addition, from a practical perspective, the normal order of information gathering and transfer is re-considered [Felder and Silverman, 1988].

This paper describes our recent experiences, seeking to bridge the art-science disciplinary divide with a series of engagements with primary school-aged students. We address the question does an integrated mix of art and science create an enhanced pathway for communication and engagement around science for primary school aged students? A sub-question then is can we enhance primary school-aged student's understanding of what science is? The authors present their work and experiences, both separately and in combination, to primary school students and ask them to contribute to the process of creating something new.

Methods: the classroom process
One of us (GO) has developed a series of art pieces based on imagining the Antarctic cryosphere through the medium of manipulated tissue paper (Figure 1). The stages include selecting and processing the material in terms of its strength and colouring, determination of shapes/system (one or several classes), planning work at the macroscale including connection with space and lighting, formation of structural sub-elements and finally joining of sub-elements and installation. These ideas have evolved a natural progression in works that can be connected approximately to the cryosphere. These works include a paper avalanche [O'Connor, 2007], beneath an ice shelf ([O'Connor, 2011], figure 2), the face of an ice shelf [O'Connor, 2013], brine tubes [O'Connor, 2014a] and the ice barrier [O'Connor, 2014b]. 


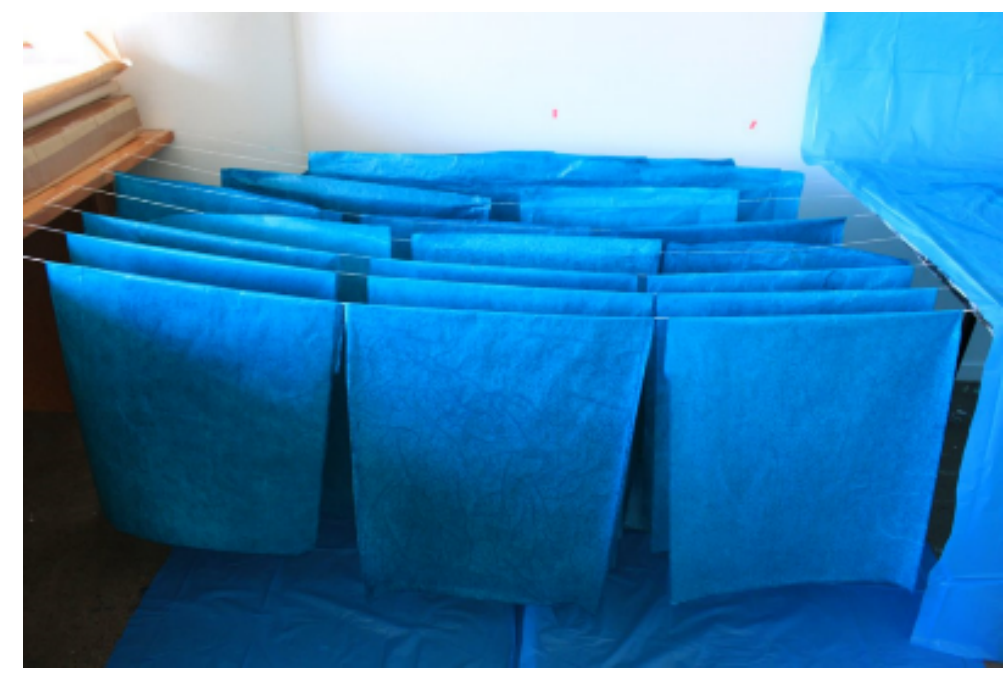

Figure 1. Material prepared for group making.

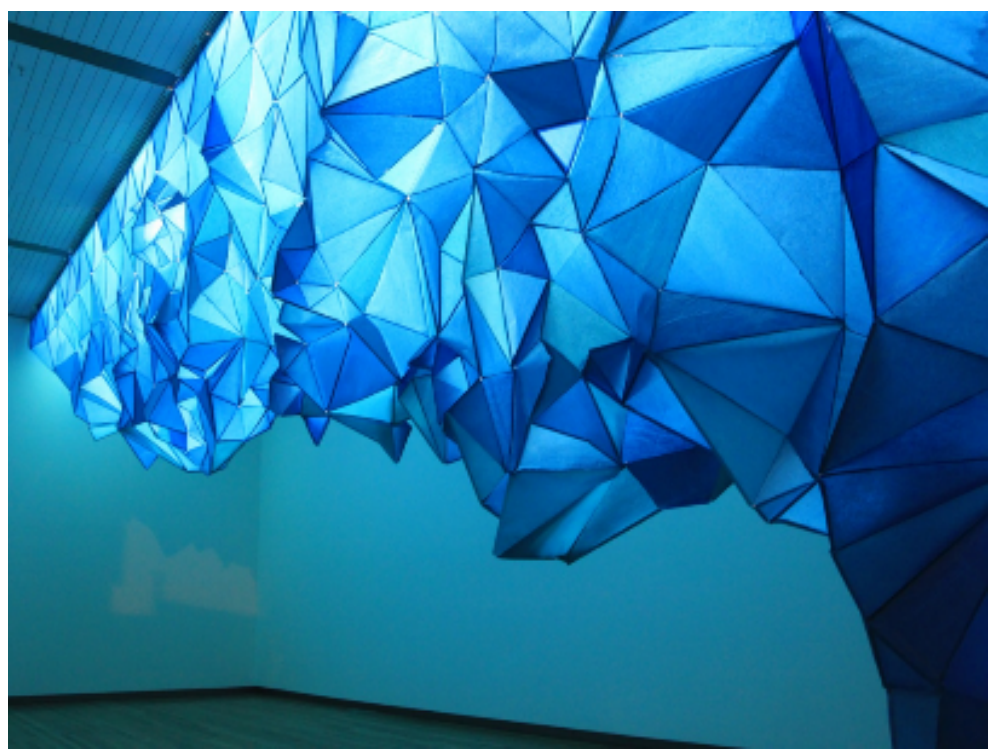

Figure 2. Art Piece — What Lies Beneath gallery installation [O'Connor, 2011].

From this progression, we have developed a classroom learning structure that puts multiple educational themes in an overarching environmental context (the connection to thematic learning is discussed later), one result of which is a collaborative art exhibition. The schools have a range of ethnicities (Table 1), and are from subset of the New Zealand national "decile system" that rates schools on the ability of their region to provide augmented funding (10 is high socio-economic regional baseline). The students were in the 5-12 year old age range and a total of around 650 students took part.

The classroom process starts with an introduction from the class teacher and then the artist takes over as facilitator of the session and talks about their working life and motivations. The importance to the artist of scientific curiosity and the history of research (in this case Antarctic) and learning is identified at this point. They introduce the work they have produced to date and how they evolve from one to another, the material and methods used and the associated environmental processes described. 
Table 1. Ethnic diversity for trial schools.

\begin{tabular}{|l|l|l|l|}
\hline & $\begin{array}{l}\text { School 1 } \\
\text { Decile 10 }\end{array}$ & $\begin{array}{l}\text { School 2 } \\
\text { Decile 6 }\end{array}$ & $\begin{array}{l}\text { School 3 } \\
\text { Decile 9 }\end{array}$ \\
\hline NZ European & $80 \%$ & $44 \%$ & $83 \%$ \\
\hline NZ Mâori & 5 & 16 & 9 \\
\hline Pacific Isl. & 1 & 10 & 2 \\
\hline Chinese & 4 & 7 & - \\
\hline Indian & - & 6 & - \\
\hline U.K./Ireland & 4 & - & 2 \\
\hline Cambodian/Khmer/Kampuchean & - & 5 & - \\
\hline Somali/Africa & - & 3 & 2 \\
\hline other & 6 & 9 & 2 \\
\hline
\end{tabular}

The scientist then provides a scientific context for the art project by talking about what they do as a researcher and introduces the sorts of questions addressed by the science and the relevance of this to the students and their world. The science in this case focuses on Antarctic ice-ocean interaction and how it relates to climate change and polar ecosystems (Figure 3). Statements to the students on the changing climate reflect present scientific consensus and make the point that the world they are going to live in is being modified by how we live today. This has a focus on climate processes but also touches on ecosystems and charismatic megafauna. As with the art, a science trajectory is also described. Expeditions to variously evocatively named remote icy locations [e.g. Stevens et al., 2013], the Drygalski Ice Tongue, the Erebus Glacier Tongue, the Ross Ice Shelf and Haskell Strait are all connected with different parts of the role ice in Antarctica plays in our global

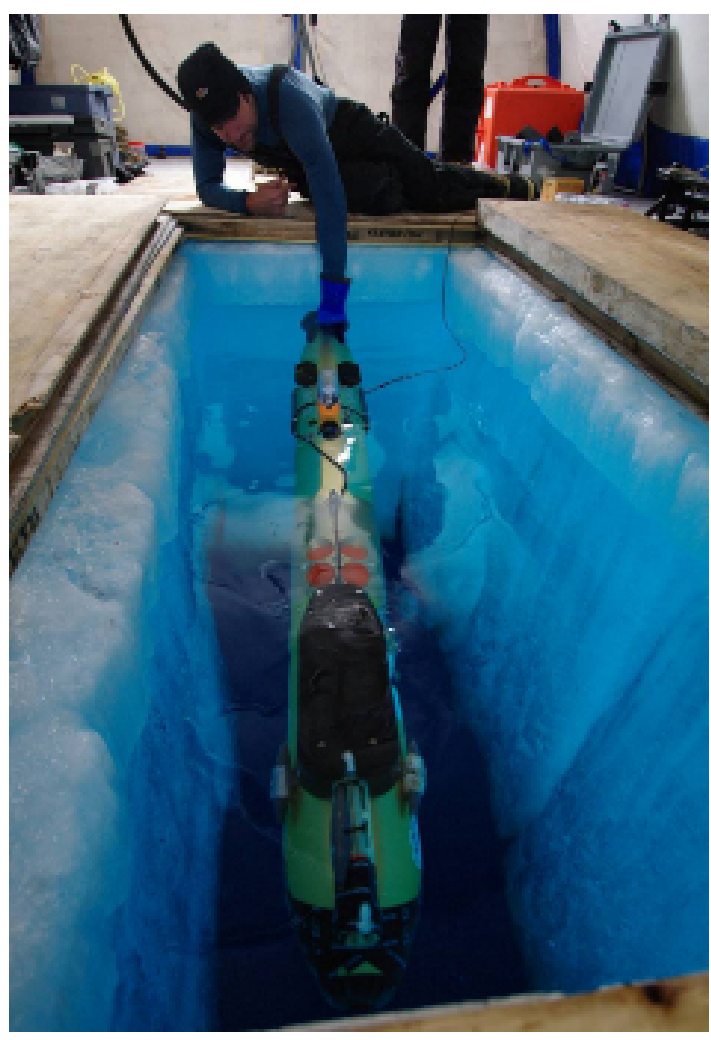

Figure 3. Science at work, an unmanned miniature submarine, combining environment, technology and physical resilience. 
system. The science has its similarities to the art in that achievable elements are joined to form a larger whole. The science in this case is detailed measurement of ocean processes, in other words measuring the small things to ultimately work out how the larger whole works.

Both protagonists describe, in broad terms, how these scientific elements are related to the art and artistic process that they have just heard about. The connection is not particularly high-level, at least in how it is presented. Concepts like (i) the shapes being the same, (ii) apparently fragile elements can be combined to generate stronger units, (iii) evolution and application of methods, (iv) ideas develop and connect from project to project, (v) imagination, collaboration and flexibility are required. The students learn that the world is not yet fully understood, and that we (i.e. they) are going to have to engage with their individual and collective creativity to expand understanding in the future.

The talks are based around projected images and video, although alternative styles should be possible depending on the presenting skills of the protagonists and the topic. The approach used here takes advantage of the inherent visual beauty of the two fields. The art is good to look at - the different shapes and forms of the work build and show the students exactly what one version of the creative process looks like. The science too can be good to look at, with a mix of natural beauty from landscapes as well as the action of the sampling.

The approach is not overly didactic. The material focuses on the work and achievements of the speakers and their immediate collaborators rather than an overarching synthesis of everything done and known in the field and beyond. Rather than placing the students in front of a seemingly unclimbable wall of knowledge, this maintains a sense of scale and achievability. The two speaking segments are around 15 minutes each and the pair of back-to-back talks are followed by a joint question time. Our experience has been that this question period can continue for as long as the class structure allows. Furthermore, to date most of the questions are around the environment and the animals. This makes sense as, at this stage of the session, the science is far more tangible. As is typical at such ages, there will be some perceptive questions amongst more routine queries about whales, ablutions, the cold and death.

Based on student-assisted work in the previous productions, the talks close with an invitation from the artist to the students to help them with the next piece. The facilitator/artist presents the task at hand - to help build components that will be integrated into an art piece (Figure 4). The students are invited to form groups of a size commensurate with class size, ability and materials. They are shown the tools, material and best techniques but given quite a loose reign on what to create. The students then interact and try different arrangements and help each other to build the basic sub-elements. In this way they form partnerships, working together to negotiate how the components connect. After some time these small groups and their work join together and this process is repeated until a larger, but manageable artistic mass is created. There are aspects of group discussion, debate, mechanical dexterity and vision around what needs to be done to get to a desired end-point. During this period (say 20 minutes) the teachers and the speakers circulate and provide advice or help, depending on the abilities of the class. At this stage, both 


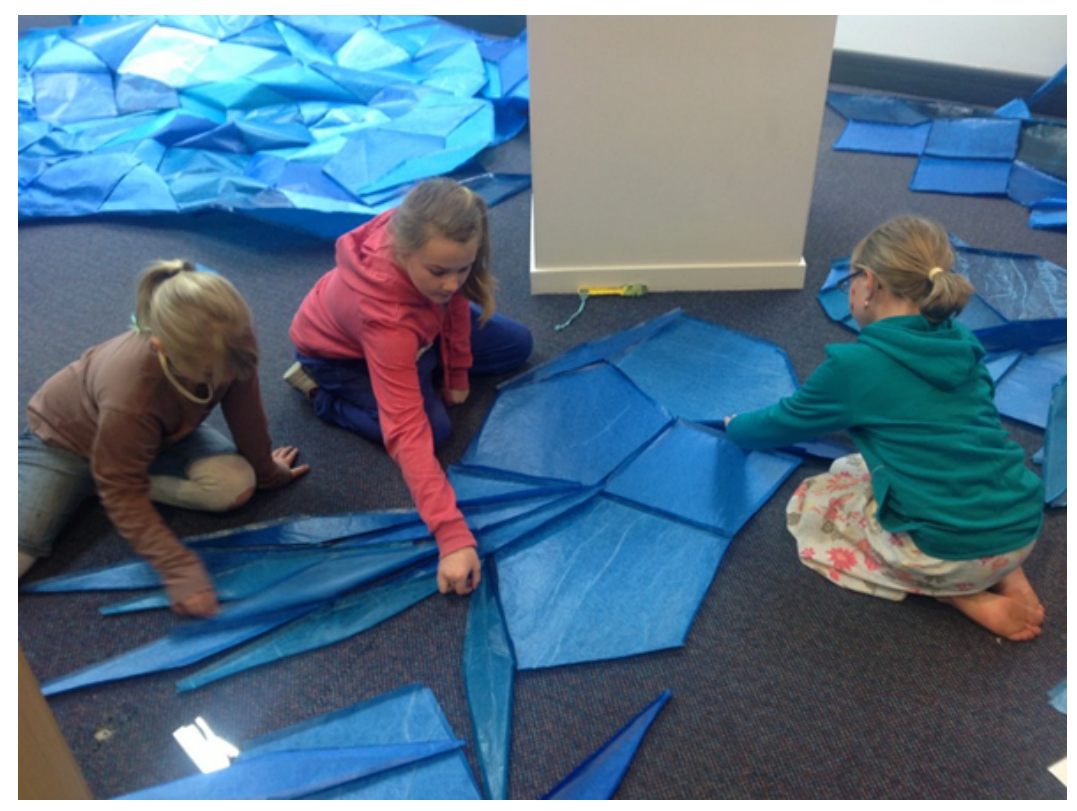

Figure 4. Students at work making shapes.

the artist and scientist are on the floor, at student-height, assisting and encouraging the collaborations, while facilitating further questioning.

Depending on class ability, the structure has been mainly about the students (i) forming groups, (ii) playing with pre-prepared material and shapes to familiarize themselves with what they are dealing with, (iii) learning the shape-joining at a fine scale and finally (iv) developing and realising a macro-scale shaping of the elements they have to work with. Importantly, these tasks, by and large, all happen in group structure.

Typically, a number of science props are brought along. As groups finish their task, they are invited to interact with the props. Oversized polar clothes are fun for the students to put on and compare. The mukluks, jackets, bibs, facemasks and multiple hats and gloves all lend themselves well to sharing some of the experience. Where space and transport has permitted we have included a real polar tent (sometimes called a Scott tent). The same attributes that make them useful in the field, they are very hardy and simple to erect, work for them in the classroom. They are also iconic for anyone familiar with polar exploration. That they are still used makes for a connection between the present and the history of scientific exploration. Groups are allowed to sit inside the tent (Figure 5). This is quite powerful as they are difficult to get inside even in street clothes, and once inside are quite evocative of being isolated.

This is followed by a clean-up and pack-up session. In the authors' experience a whole new suite of questions emerge from the less confident/vocal students again many of which are highly perceptive. The session closes with a brief summary from the artist as facilitator and an explanation of how the works the students have produced will contribute to upcoming exhibitions. 


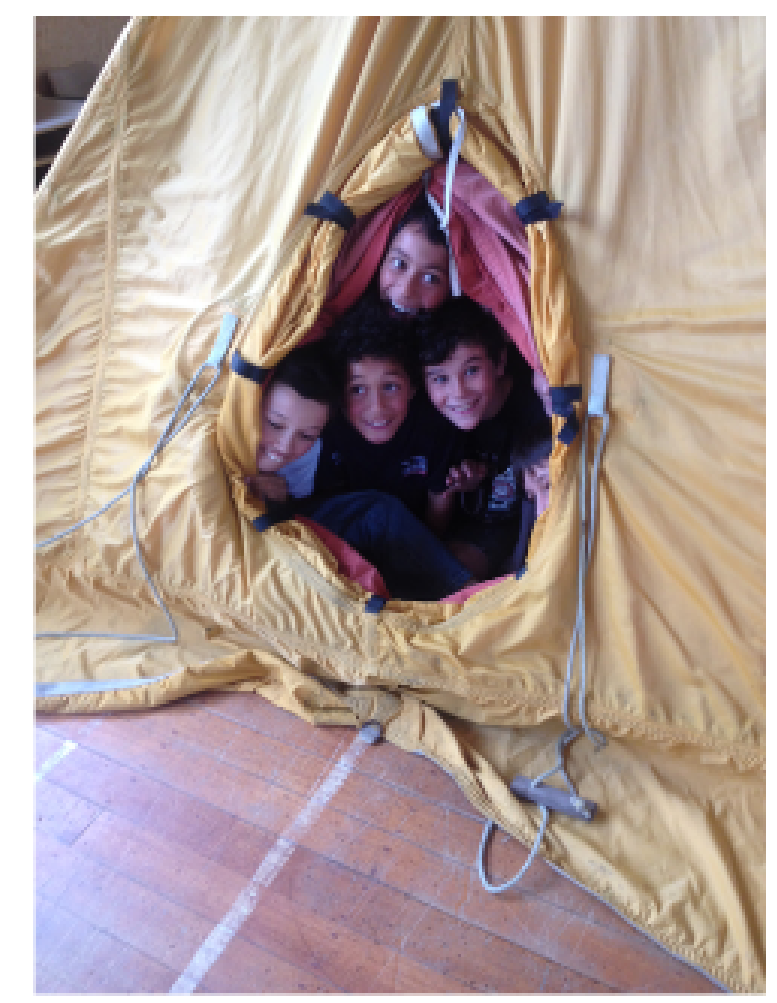

Figure 5. Faces in tent, a reward for listening and collaborating.

\section{Communication}

A range of communication pathways are contained in the approach. The "old person out the front talking" gives way to discussion between teachers, question and answers, peer debate during the making, through to group and individual questions. This needs an engaging entry point. The heroic era of discovery is endlessly fascinating and clearly connects to the basis of the human condition. A century after the fact, probably only a modest proportion of students would be familiar with the trials of early polar exploration. Many however, follow up and learn more. This is brought into focus by GO's introduction around her motivation being the homeward journey of the entombed explorers of Robert Falcon Scott's unsuccessful return from the South Pole. This is referenced in the science component whereby one of the scientists (Edward Nelson) on Scott's last expedition is connected to in terms of the longevity of their work [Langhorne et al., 2015] as well as their hardy constitution. It also connects to the notion of the ice, environment and climate as not being fixed. Climate variability becomes a real thing - there's a 100 year old picture of someone who actually measured the very things that we are now re-measuring and seeing change. It humanizes climate scales.

There are two question-and-answer phases of the session that are useful for getting the students comfortable and perhaps making the process seem not so didactic. The opening period, prior to the presentations, is a bit of dialogue with the students on what they know about the subject. "Who's seen an iceberg? What's the coldest anyone has been?" The closing session question and answer period is on art and science in conjunction, although there is a bias towards the science as this was the last element presented to them. The trajectory of this discussion is dependent largely on the whims of the student group although the focus can be loosely steered by the experience of the art/science instructors. It can focus on the animals seen, 
nitty-gritty of living on ice ("where's the toilet?"), through to the protagonists - "(student) how come you know so much?" (scientist) "because I'm old", (student) "how old?". While humorous, it reflects the at-ease nature of the interaction.

The work promotes to the students the concept that the world is not yet completely known and that our imaginations are required to fully map it. This is then connected to the "making" element of the workshop where the students are explicitly requested to use creativity to piece together shapes - to try different arrangements, to connect them with things they know about (birds, snowflakes etc.) and to imagine how they might make a much bigger object.

When so much is achievable so quickly these days through computers and personal digital assistants, the time required for manual labour is somewhat immutable. Certainly, methodologies for speeding up the hand-making process and recycling are discussed and implemented, but the advantages to the wider outcomes of working in such a manual way are explained and discussed. These are somewhat intangible but the group-making process helps clarify some of the benefits, as well as being enjoyable and implicitly constructive in terms of team-building and development of collaborative techniques.

This concept of time being required to build individual elements is extended into the time it takes to achieve and evolve different projects. The artist's ideas evolve from early inspiration through to trying different approaches, bergs, ice shelves, brine. Similarly, science evolves through a sequence of expeditions, ideas, technology and documentation. This directly evokes little c creativity $(\mathrm{LcC}$, [Craft, 2000]) rather than large seismic shifts in thinking [Kuhn, 1962], which is also in keeping with climate science's development in recent decades. This is not to suggest a slow rate of change however. The extraordinary growth in the many $\mathrm{LcC}$ advances mean that our understanding and behaviour as a species is rapidly evolving on the back of multitudinous small steps.

The use of material is highly relevant in the present context [Guerra and Zuccoli, 2012]. Not only are the pros and cons of different materials explored, consideration is also given to repurposing and recycling. Benefits in creative thought have been seen to emerge from such approaches to material. Something fragile is made strong through coating and structural engineering - but achieved through the "art process". Furthermore, this is extended as the pieces evolve from inside gallery works through to outdoor large-scale installations and the material shifts from tissue to Tyvek ${ }^{\mathrm{TM}}$, a heavy-duty fabric used for outdoor displays. This gives the students an appreciation of how to gauge appropriate materials for conditions which is an integral part of working in and with the environment.

Implicit in this examination of material is discussion around colours and translucency. This is a tangible connection between art and science. The visual, something entwined with much of our dialogue with art, is fundamentally physics - visible radiation. The colours we see are a manifestation of the combined biophysics of vision and the physics of illumination, absorption and reflection. The rules governing these interactions are made use of directly in order to achieve the final result in the art piece. Discussion around colour and form connects with the cryosphere, but also has its own inherent aesthetic beauty. Both artist and scientist 
are clear in their respect and engagement with the "other side". The artist makes reference to needing "facts" and experience and the scientist makes connections with creativity and the desire to create things. The latter direction - art driving the science - is perhaps less readily understood and so consequently potentially there is more to be learnt by building on this.

The making-process involves creation of shapes and modifying them to enable construction and connection with everyday tools. Ideas around repeatability and strength are imparted. At this point it is useful to have some engineering knowledge on hand to explain the mechanics of connecting many flat pieces to make a 3D whole. The artist has innate skills and experience in how things work best. The scientist can then identify things that do and don't connect with mechanical principles. There is a direct difference in the experience. The artist is remotely integrating information-streams to inform their work, whereas the scientist has direct quantitative and empirical experience. The geometric/structural system used in the art is described in terms of toys like Lego ${ }^{\mathrm{TM}} / \mathrm{Meccano}^{\mathrm{TM}}$. This instantly associates the task at hand with systematic creation and the idea that the possibilities are essentially infinite. As an aside it must be recognised that this is limited by the financial support for the students - i.e. not all students can afford to have Lego ${ }^{\mathrm{TM}}$ in their house.

However, this also reflects freedom and constraints - the artist can gather and collect widely whereas the scientist is constrained by their experience. This is of course situation-dependent as the reverse is possible whereby the artist has travelled somewhere and the scientist is using remotely sensed or modelled data.

One issue that proves challenging in the science segment of the talking is the strategy for presenting charismatic megafauna (penguins, whales, seals etc.). Our present approach is to show the animals last. Human fascination with fellow fauna over say flora or the geophysical world shines through comprehensively. Images of penguins and seals cause a seismic shift in the audience attention which, whilst being unfailing high all the way through, steps up to audible excitement (recall that this is after $\sim 30$ minutes of the students listening to talks). Rather than fully embracing this (one could, after all, talk only about penguins and seals), we emphasize that other things are at play too in the natural world and that there is no divide between "natural" and "physical" worlds. This brings the environment to the foreground and so, for Antarctica, helps broaden ones perspective beyond "Happy Feet" (Happy Feet refers either to an animated movie about penguins or the eponymous real-life emperor penguin that was found on a New Zealand beach, sick and lost, restored to health and returned to somewhere near its habitat with great media attention).

Perhaps it should have been obvious a priori, but the authors were surprised by the impact of "The Tent" as a prop in its first use with the initiative. It is imposing on the classroom scale and evocative. It is very different to any tent the students would have experienced, yet it is externally familiar from historical photographs. Other than the noise and temperature, once inside you could really be an explorer. You get a sense of the bubble of life imposed and the inexorable proximity of your companions. Elements like the vents, the drying net and the simple but effective entrance bring to the students a sense of the experience of being on the ice. The manual and student-led elements lead to a playful classroom situation so that the 
students are learning almost without realising they are doing so. It provides a soft entry into what might otherwise be considered hard topics, and also that some so-called soft topics have value too.

We have found the information exchange process completely elastic. In some ways the concept is a one size fits all in that while language might be changed to suit different audiences, little else needs to be modified. This is in part because of the student-led nature of much of the process allows them to extend their discoveries to the most appropriate level. There is very little we have needed to change in a structural sense in order to align with different audiences. This extends from peer groups all the way through to school groups with learning difficulties. In the case of learning difficulty students, group sizes need to be smaller but students with various difficulties were able to engage with and contribute to the process of making art and the background science. This reflects the broad extent of the human experience covered. There will be few in any audience who could legitimately claim to have full understanding of all aspects being presented, yet through the connections made it is also clear that the concepts, from tissue paper through to climate, are in fact a continuum of which we can all identify with something, and so interesting to all parties.

Connecting art and science is one of the prime motivations of the present work. The students see that the approaches, motivations pattern and structure have similarities across the disciplines [Andreasen and Ramchandran, 2012] — and that there is mutual respect across the disciplines. No one theme is more important that another. For those students who have developed silos, as for the general public, there is an element of information delivery by stealth. The "tech-geek" student who cares not for art, finds themselves making icebergs out of tissue paper. The "arty kid" wonders what it would be like to go on a scientific mission? Older minds definitely see the fields as being siloed and separate. This is made all the more clear because discussion at the adult/peer level is around how art and science are not connected (although feedback has also been that the paired talks break this distinction down).

The approach activates different students through a process of democratization. By carrying through a range of approaches and information dissemination techniques different learning/teaching combinations [Felder and Silverman, 1988] are initiated. This can re-energise a class by giving a different balance of focus and empowerment to students who don't normally dominate. Special-needs students (e.g. autistic) who typically might be a disruptive influence in the standard class environment, when given a topic that they could connect to through their own extended knowledge (e.g. obscure details about the Titanic and its encounter with an iceberg), go on to both participate constructively and demonstrate to their peers that they have much to contribute in the right framework.

The cross-disciplinary points made in the talks relate to geography, form, pattern and work processes. Clearly, this isn't enough for a proportion of adult audiences. But a seven year old doesn't see them separately. Instead, they see themselves making icebergs, at the same time as hearing how you measure them, and why they are important to them and their family and culture now and in the future. Thematic learning [Lipson et al., 1993] seeks to synthesize a range of classes (mathematics, geography, art...) under a single topic or theme (e.g. cities, Antarctica or the 
ocean). The students still have separate mathematics, geography, art classes etc. but focus them all on the same broad theme. In the present approach the disciplines are all intermingled. "Geometry is used to make Art that is based on Geography that is about the History of research into the Environment that uses Mathematics that ...". In this way there is direct contact between science and art and the benefits that accrue [Marshall, 2005].

There are a multiplicity of communication aspects to the learning process whereby cognitive, sensory and environmental factors combine [Rayner and Riding, 1997]. In the present approach different sensory approaches (visual, auditory, tactile) interplay with analytic and discriminatory thinking and a collaborative environment seeking to evoke Antarctica. In this way it differs from thematic learning where different fields and approaches focus on one theme. Instead here we intend that the disciplinary connection happens more fundamentally so that there are exchanges in approach, irrespective of the goal.

There is no wrong answer to developing science-inspired art, although there are results that are perhaps less direct contributions to the end-point. The open-endedness of science can be at odds with normal classroom education [Hadzigeorgiou, Fokialis and Kabouropoulou, 2012] in that real-world science "often has ill-structured problems admitting multiple solutions" and that (despite what is often promoted) "there is no universal scientific methodology" [Hadzigeorgiou, Fokialis and Kabouropoulou, 2012, page 606]. Art serves to validate these issues as these themes are clearer to school age students within the art world and the present activity serves to show that art and science are closer to each other than we think.

\section{Outcomes}

This student-led exploration and learning generates a wide range of outcomes. At a fundamental level, one shouldn't under-estimate the simple power of students meeting and interacting with real live artists and scientists and seeing them connect and respect one-another's field and hear about how they got to be what they are. To a degree, the artist and scientist have stopped talking through one-another [Kuhn, 1962]. This is not simple to achieve because it can't really be simulated as students are perceptive and can identify a manufactured reality. This combination of creative perspectives will become easier to form if the process feeds back so that future artists and scientist are more connected with a broader spectrum of creativity, i.e. the approach here is required as a prerequisite for the development of future practitioners able to proceed with the process - a positive feedback.

Evaluation is difficult because of the scale of the project and the age of the students. Here it is encapsulated in some anecdotal outcomes. Teacher comments have been collated and include comments like:

\footnotetext{
- student uninterested in reading started reading about Antarctica - a massive transition for the student's development.

- making their own artworks in the same form

- disruptive learning-difficulties student seen in new light by peers
} 


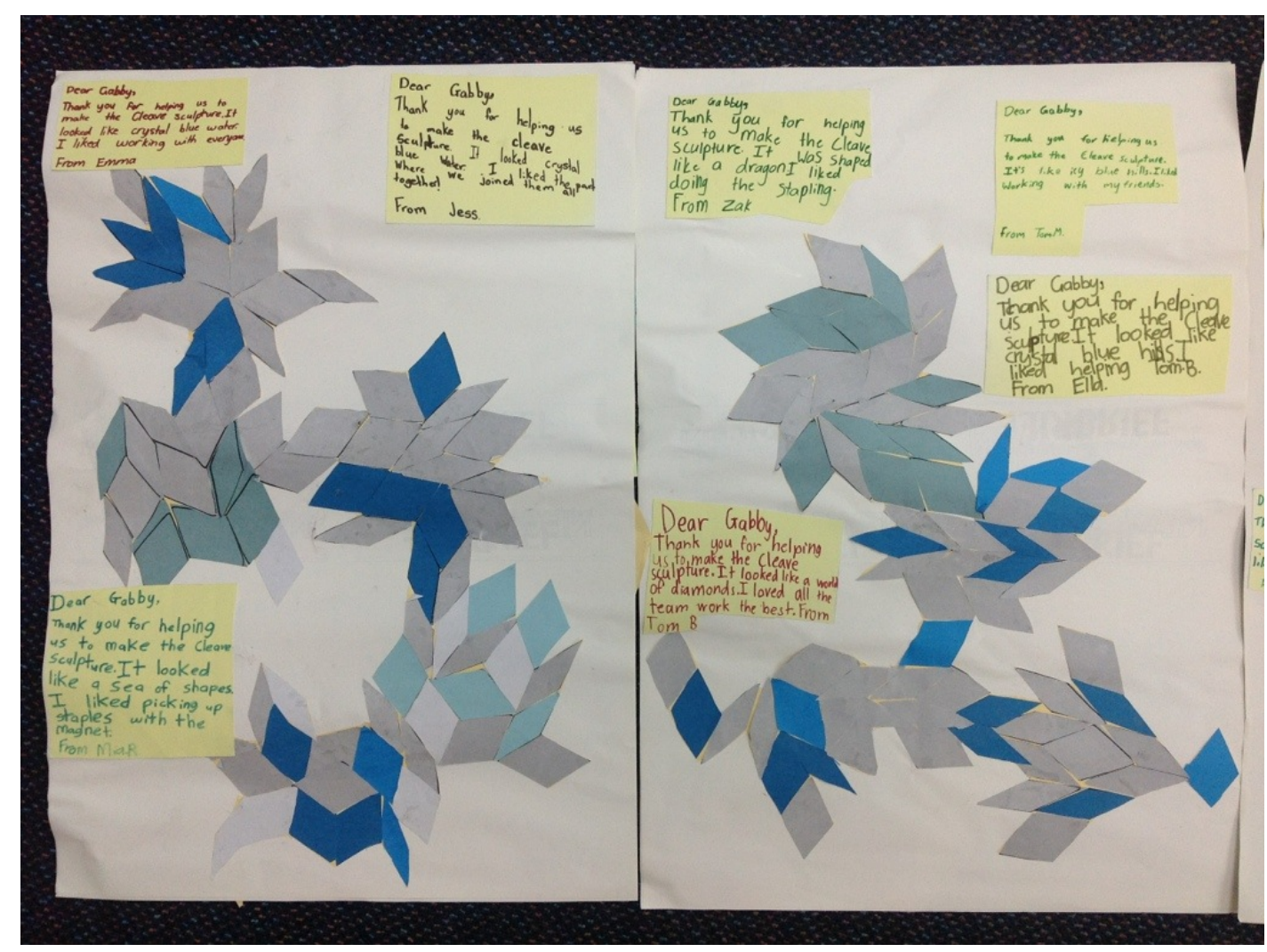

Figure 6. Feedback comments and artistic interpretation from students to artist/scientist via teacher.

- the students better understand what science is

- family members entrained into the process through family discussion.

The students themselves have been invited to be part of this process through their own written feedback (Figure 6). We could not identify a bias in engagement associated with diversity and/or socio-economic baseline (i.e. Table 1) that manifest itself above other factors like class size and time of day relative to lunch.

The format democratizes the learning process in a number of ways. The students get to work on a bona fide art piece. Furthermore, the otherwise scientist gets described as an Overqualified Assistant. This is evidence of how democratic the process is, in that the work is not being produced by some intangible elite. Rather, they get to be a legitimate part of the development, all the more so in that the making somewhat dictates the evolution of the structure. And they see the "experts" along-side them - being the same.

The artist starts the presentation with the connection to art school - these skills and the understanding underpinning them require learning as much as scientific numbers. Beyond this, at least in its present form, the art side does not present a "how to be me" recipe other than direct inspiration. The science side is more direct. The presentation is entirely unambiguous at various points - "if you want to do this sort of thing, do more mathematics and learn to tie knots". This pushes the point that quantitative skills are essentially for engaging with the future but that some grounding in the tangible is also needed. 
The work is student-led. Not just at the process level whereby the groups make decisions and choices around shapes and how to work together to build them, but also in what elements excited them the most at an individual level. This generates a learning legacy beyond the collaboration/team work, problem solving and group learning opportunities. This might be sufficiently great that they then carry on with their own exploration/research at an individual level. This has included reading about penguins, or learn how far away Antarctica really is, or discover more about submarines or artists. Seeds are sown in the making phase that then might germinate in research time. In this way there is a longevity to the ideas.

In some ways the present approach of directly involving students in exhibited art is a social promotional campaign seeking to distribute knowledge and education around climate. Messages are framed around the environment, reactions to its evolution and the creativity required to address these issues, even if indirectly. The students are turned into ambassadors for art and science, both separately and in combination. They engage their families in what they've learnt and literally nag them to attend the gallery displays. At a basic level this is effective and efficient knowledge-connected "social marketing" [Kennedy, 2010] but also it integrates the ideas being talked about into family discussion.

In terms of the questions posed initially does an integrated mix of art and science create an enhanced pathway for communication and engagement of science for primary school aged students? And can we enhance primary school-aged student's understanding of what science is? Certainly, the first question can be answered in the affirmative, at least with qualitative evidence generated here. The answer to the second question is less clear. There is a possibility that by only presenting one approach to science at such a developmental stage in the student's understanding, the activity may serve to generate confusion as the student encounters different approaches. However, in the absence of some over-arching pan-thematic initial class on science, this will happen regardless.

The present approach to engaging students is financially economic but slow. A small investment in time and resources, on top of support of the protagonists' activities, has the potential to generate a substantial legacy. It does however require a generational perspective on changing intellectual focus as we need to wait for the students to become adults before the impacts are felt.

The approach benefits from protagonist-combinations that have the experience and credibility to convince the students of the veracity of the combination. It is not known how easily this might be "manufactured". Could it be produced with a couple of hour's discussion between newly introduced artist and scientist? Or does it require, as in the present case, a multi-year, multi-activity collaboration? Could other manifestations work, like teams for example? Could the process benefit from being revisited in a time-longitudinal sense? Might the collaboration and interaction be developed in some way over the internet? These questions suggest that a unique and powerful approach to enhanced communication and learning outcomes with a long impact can emerge from the art-science nexus. 
Acknowledgments The authors wish to thank Katharine Allard, Brett Grant and Natalie Robinson for their assistance. The work was made possible through support from NIWA, Royal Society of New Zealand Marsden Fund, the New Zealand Antarctic Research Institute, Wellington City Council Creative Communities and Christchurch City Council for IcefestNZ 2014. We also thank the staff and students of Miramar Central, Plateau and Wadestown Primary Schools.

Andreasen, N. C. and Ramchandran, K. (2012). 'Creativity in art and science: are there two cultures?' Dialogues in clinical neuroscience 14 (1), p. 49.

Craft, A. (2000). Teaching Creativity: Philosophy and Practice. New York, U.S.A.: Routledge.

Felder, R. M. and Silverman, L. K. (1988). 'Learning and teaching styles in engineering education'. Engineering Education 78 (7), pp. 674-681.

Guerra, M. and Zuccoli, F. (2012). 'Finished and unfinished objects: supporting children's creativity through materials'. Procedia-Social and Behavioral Sciences 51, pp. 721-727.

Hadzigeorgiou, Y., Fokialis, P. and Kabouropoulou, M. (2012). 'Thinking about Creativity in Science Education'. Creative Education 3, pp. 603-611. DOI: 10.4236/ce.2012.35089.

Kennedy, A. L. (2010). 'Using community-based social marketing techniques to enhance environmental regulation'. Sustainability 2 (4), pp. 1138-1160.

Kuhn, T. (1962). The structure of scientific revolutions. Chicago, U.S.A.: University of Chicago Press.

Langhorne, P. J., Hughes, K. G., Gough, A. J., Smith, I. J., Leonard, G. H., Williams, M. J. M., Stevens, C. L., Robinson, N. J., Rack, W., Price, D., Mahoney, A. R., Haas, C. and Haskell, T. G. (2015). 'Ice shelf-ocean heat flux: spatial and temporal distribution of platelet ice around coastal Antarctica'. Geophys. Res. Lett. 42, pp. 5442-5451. DOI: 10.1002/2015GL064508.

Lipson, M. Y., Valencia, S. W., Wixson, K. K. and Peters, C. W. (1993). 'Integration and thematic teaching: Integration to improve teaching and learning'. Language Arts 70 (4), pp. 252-263. URL: http: //www . jstor . org/stable/41482091.

Marshall, J. (2005). 'Connecting art, learning, and creativity: A case for curriculum integration'. Studies in Art Education 46 (3), pp. 227-241.

McArdle, F. and Wright, S. K. (2014). 'First Literacies: Art, Creativity, Play, Constructive Meaning-Making'. In: Literacy in the Arts. Springer International Publishing, pp. 21-37.

Nelson, C. A. (2000). 'Neural plasticity and human development: the role of early experience in sculpting memory systems'. Developmental Science 3, pp. 115-136. DOI: $10.1111 / 1467-7687.00104$.

O'Connor, G. (2007). Avalanche, recycled envelopes. [ $4 \mathrm{~m} \times 2 \mathrm{~m}]$. Toi Poneke and the NZ National Library, Wellington, NZ.

- (2011). What Lies Beneath, tissue paper, lacquer, staples, light. [12 $\mathrm{m} \times 4 \mathrm{~m} \times 2 \mathrm{~m}]$. City Gallery, Wellington, NZ.

- (2013). Cleave, tissue paper, lacquer, staples, light. [12 $\mathrm{m} \times 4 \mathrm{~m} \times 2 \mathrm{~m}]$. Pop-Up Gallery, Wellington, NZ.

- (2014a). Heavy Water, tissue paper, lacquer, staples, light. [6×6 $\mathrm{m} \times 0.1 \mathrm{~m} \times 0.1 \mathrm{~m}]$. Expressions Gallery Upper Hutt, NZ.

- (2014b). Inland Ice, Tyvek, lacquer, staples, light. [24 $\mathrm{m} \times 4 \mathrm{~m} \times 2 \mathrm{~m}$ ]. IceFest, Christchurch, NZ. 
Rayner, S. and Riding, R. (1997). 'Towards a categorisation of cognitive styles and learning styles'. Educational Psychology 17 (1-2), pp. 5-27.

Stevens, C. L., Sirguey, P., Leonard, G. H. and Haskell, T. G. (2013). ‘Brief Communication: The 2013 Erebus Glacier Tongue Calving Event'. The Cryosphere 7, pp. 1333-1337. DOI: 10.5194/tc-7-1333-2013.

Wolfradt, U. and Pretz, J. E. (2001). 'Individual differences in creativity: personality, story writing, and hobbies'. Eur. J. Pers. 15, pp. 297-310. DOI: 10.1002/per. 409.

Authors

Gabby O'Connor is a Wellington-based installation artist who produces large-scale site-specific work; transforming everyday materials into beautiful and complex artworks that communicate sophisticated ideas. O'Connor often works collaboratively: from cutting-edge scientists to community groups. Her works exist as installations in their own right, and also act as a bridge between art and science. E-mail: gabrielle.1.oconnor@gmail.com.

Associate Professor Craig Stevens is an oceanographer who holds a joint position with the New Zealand National Institute for Water and Atmospheric Research and the Department of Physics at the University of Auckland. His research focus is on the mechanics of extreme ocean environments. He uses these experiences, placed in a societal context, to help explain why we do environmental science, what it means and why we should keep doing it. E-mail: Craig.Stevens@niwa.co.nz.

How to cite

O'Connor, G. and Stevens, C. (2015). 'Combined art and science as a communication pathway in a primary school setting: paper and ice'. JCOM $14(04)$, A04. 